\title{
Malignant lymphomas in Waldeyer's ring in Asian countries: Association with histologic types and Epstein-Barr virus
}

\author{
NAOKI WADA ${ }^{1}$, MARIA FRANCISCA HAM ${ }^{2}$, SHIGEKI FUJITA ${ }^{1}$, \\ HIROKI SHIMAZU ${ }^{1}$, ANTONIUS N. KURNIAWAN ${ }^{2}$, ENDANG S.R. HARDJOLUKITO ${ }^{2}$, \\ EVLINA SUZANNA ${ }^{3}$, XIN-SHAN JIA ${ }^{4}$, WOO-ICK YANG ${ }^{5}$ and KATSUYUKI AOZASA ${ }^{1}$ \\ ${ }^{1}$ Department of Pathology, Osaka University Graduate School of Medicine, Osaka, Japan; \\ ${ }^{2}$ Department of Anatomical Pathology, Faculty of Medicine, University of Indonesia - Dr Cipto Mangunkusumo \\ National General Hospital, Jakarta; ${ }^{3}$ Anatomical Pathology, Dharmais National Cancer Center Hospital, \\ Jakarta, Indonesia; ${ }^{4}$ Department of Pathology, China Medical University, Shenyang, P.R. China; \\ ${ }^{5}$ Department of Pathology, College of Medicine, Yonsei University, Seoul, Korea
}

Received April 17, 2008; Accepted June 12, 2008

DOI: $10.3892 / \mathrm{mmr} 00000007$

\begin{abstract}
The present study examines clinicopathologic findings and their association with the Epstein-Barr virus (EBV) in Waldeyer's ring lymphomas (WRLs) from Indonesia (91 cases), P.R. China (31 cases), Korea (101 cases) and Japan (61 cases). Waldeyer's ring (WR) was categorized into upper and lower parts comprising the pharyngeal and tubal tonsils (upper WR) or palatine and lingual tonsils (lower WR), respectively. Diffuse large B-cell lymphoma (DLBCL) predominated in the lower WR in all countries at a frequency of 78.9-100\%. Natural killer/T-cell lymphoma (NKTCL) was predominant in the upper WR in China, Korea and Japan at a frequency of 50-62.5\%, while in Indonesia it occcurred at a frequency of less than $10 \%$. On the whole, patients with NKTCL were significantly younger (median 43 years) than those with DLBCL (57 years). Patients with DLBCL in the lower WR were significantly younger in Indonesia (median 50 years) than in China (63 years) or Japan (69 years). The percentage of EBV-positive cases was much higher in NKTCL (78.6-100\%) than in DLBCL (2.2-6\%). This study evaluates the differences between East and Southeast Asian countries in terms of histologic type and age distribution in WRLs categorized by the location of the lesions in WR.
\end{abstract}

\section{Introduction}

Waldeyer's ring (WR), which comprises the pharyngeal, tubal, palatine and lingual tonsils, is a common site for the devel-

Correspondence to: Dr Katsuyuki Aozasa, Department of Pathology (C3), Osaka University Graduate School of Medicine, 2-2 Yamadaoka, Suita, Osaka 565-0871, Japan

E-mail: aozasa@molpath.med.osaka-u.ac.jp

Key words: malignant lymphoma, Waldeyer's ring, diffuse large B-cell lymphoma, natural killer/T-cell lymphoma, Epstein-Barr virus opment of malignant lymphomas, and exclusively of nonHodgkin's lymphomas (NHLs). Conventionally, WR is categorized into upper and lower parts comprising the pharyngeal and tubal tonsils (upper WR) and the palatine and lingual tonsils (lower WR). It is well known that diffuse large B-cell lymphoma (DLBCL) is the most common type of Waldeyer's ring lymphoma (WRL) $(1,2)$. However, the distribution of the histologic types of WRL between the upper or lower WR has not been fully evaluated, neither have cases of WRL in different countries been compared. The upper WR is adjacent to the posterior nasal cavity and appears to occasionally be associated with extranodal natural killer/T-cell lymphoma (NKTCL) of the nasal type.

Epstein-Barr virus (EBV), a $\gamma$-herpesvirus, is transmitted among the human population by mucosal secretions. EBV infection usually occurs subclinically early in life, but may be symptomatic if first contact is delayed until adolescence. Most adults worldwide present serologic evidence of EBV infection. An association between EBV and human lymphomas, including endemic Burkitt's lymphoma, Hodgkin's lymphoma and NHLs of either B-, T- or NK-cell immunophenotypes, has been reported $(3,4)$. EBV has on occasion been reported in WRL (5-7), but the EBV-positive rate in relation to WRL location in WR, histologic type and geographic location has not been evaluated to date.

In this study, the histologic features of WRLs in terms of location in the upper or lower WR and their association with EBV infection were examined in cases from East (China, Korea and Japan) and Southeast (Indonesia) Asian countries.

\section{Patients and methods}

WRL specimens and immunohistochemistry. A total of 284 cases of WRL in the early stages of the disease (clinical stages I and II) from East and Southeast Asian countries were collected: 91 from the University of Indonesia, Dr Cipto Mangunkusumo National General Hospital (56 cases) and Dharmais National Cancer Center Hospital (35 cases) (Jakarta, Indonesia), 31 from China Medical University (Shenyang, 
Table I. Distribution of histologic types of Waldeyer's ring lymphomas in Asian countries.

\begin{tabular}{|c|c|c|c|c|c|c|c|}
\hline \multirow[b]{2}{*}{ Country } & \multirow[b]{2}{*}{ WR Location } & \multirow[b]{2}{*}{ No. of cases } & \multicolumn{5}{|c|}{ Histologic type } \\
\hline & & & DLBCL (\%) & FL & NKTCL (\%) & PTCL-u & Other \\
\hline \multirow[t]{3}{*}{ Indonesia } & Lower & 70 & $70(100.0)$ & & & & \\
\hline & Upper & 21 & $19(90.5)$ & & $2(9.5)$ & & \\
\hline & Total & 91 & 89 (97.8) & & $2(2.2)$ & & \\
\hline \multirow[t]{3}{*}{ China } & Lower & 23 & $20 \quad(87.0)$ & & $3(13.0)$ & & \\
\hline & Upper & 8 & $3(37.5)$ & & $5(62.5)$ & & \\
\hline & Total & 31 & $23 \quad(74.2)$ & & $8(25.8)$ & & \\
\hline \multirow[t]{3}{*}{ Korea } & Lower & 76 & $60 \quad(78.9)$ & 5 & $3 \quad(3.9)$ & 7 & 1 \\
\hline & Upper & 25 & $5 \quad(20.0)$ & & $15(60.0)$ & 1 & 4 \\
\hline & Total & 101 & $65 \quad(64.4)$ & 5 & $18(17.8)$ & 8 & 5 \\
\hline \multirow[t]{3}{*}{ Japan } & Lower & 51 & $48 \quad(94.1)$ & 1 & $1 \quad(2.0)$ & 1 & \\
\hline & Upper & 10 & $2(20.0)$ & 1 & $5(50.0)$ & 1 & 1 \\
\hline & Total & 61 & $50 \quad(82.0)$ & 2 & $6 \quad(9.8)$ & 2 & 1 \\
\hline
\end{tabular}

${ }^{a}$ Anaplastic large cell lymphoma, mantle cell lymphoma, Burkitt's lymphoma and Hodgkin's lymphoma. WR, Waldeyer's ring; DLBCL, diffuse large B-cell lymphoma; FL, follicular lymphoma; NKTCL, natural killer/T-cell lymphoma; PTCL-u, peripheral T-cell lymphoma, unspecified.

P.R. China), 101 from Yonsei University (Seoul, Korea), and 61 from Osaka University Graduate School of Medicine (Osaka, Japan). Brief clinical information, including patient age at diagnosis of WRL, gender and location of the primary lesion, was available for all cases. Histologic specimens from all cases were fixed in $10 \%$ formalin and routinely processed for paraffin embedding. Histologic sections $(4 \mu \mathrm{m})$ were stained with hematoxylin and eosin (H\&E), and the immunoperoxidase procedure (ABC method) was applied. Monoclonal antibodies used for immunophenotyping were CD20, CD79a, CD3, CD8, CD5, CD30, Bcl-2 (DakoCytomation, Glostrup, Denmark; dilutions of 1:400, 1:100, 1:50, 1:100, 1:100, 1:50, 1:100, respectively), CD4 (Novocastra Laboratories, Newcastle, UK; 1:40), CD10, CD56 and Cyclin D1 (Nichirei Biosciences, Tokyo, Japan; all used as prediluted antibodies), and TIA-1 (Immunotech, Marseille, France; 1:100). Each case was initially diagnosed by pathologists at each institute, and all cases were reviewed by K.A. to confirm diagnosis.

In situ hybridization. RNA in situ hybridization using the Epstein Barr encoded RNA (EBER-1) probe was performed to examine the presence of the EBV genome in formalin-fixed paraffin-embedded sections according to a previously described method, with some modifications (8). Briefly, a 30-base oligonucleotide probe, 5'-AGACACCGTCCTCACCACCCG GGACTTGTA-3', served as both sense and antisense for a portion of the EBER-1 gene, which is a region of the EBV genome that is actively transcribed in latently infected cells and was synthesized using a DNA synthesizer. As a positive control, the Raji cell line was used. As a negative control, hybridizing mixture containing sense or antisense probes after
RNase treatment was used. Samples for in situ hybridization were not available from 18 Korean patients. Cases were defined as EBV-positive when in situ hybridization yielded positive signals in the nuclei of $>1 \%$ of the proliferating cells.

Statistical analysis. Fisher's exact probability test or the $\chi^{2}$ test were used to determine statistically significant differences. A p-value $<0.05$ was considered statistically significant.

\section{Results}

The number of cases and the distribution of histologic type of WRL in WR are summarized by country in Table I. Age and gender ratios are summarized in Table II. The ratio of WRL in the lower to upper WR ranged between 2.9:1 and 3.3:1 in Indonesia, China and Korea, whereas in Japan it was 5.1:1, indicating a preponderance of WRL cases in the lower WR in that country. However, this difference was not significant. In all countries, the vast majority of WRLs in the lower WR were B-cell lymphomas, in particular DLBCL. In the upper WR, NKTCL occurred more frequently than DLBCL in China $(62.5 \%)$, Korea $(60 \%)$ and Japan $(50 \%)$, a significantly higher occurrence than that seen in Indonesia $(9.5 \%)(\mathrm{p}=0.0079$, $\mathrm{p}=0.0004, \mathrm{p}=0.022$, respectively).

In all, the frequency of patients over 60 years of age in NKTCL cases $(8.8 \%)$ was significantly lower than in DLBCL cases $(40.5 \%)(p=0.0003)$. Limited to the lower WR, the frequency of patients over 60 years of age with DLBCL was significantly lower in Indonesia $(25.7 \%)$ compared to China $(55 \%)$ and Japan $(70.8 \%)(\mathrm{p}=0.013, \mathrm{p}<0.0001$, respectively). The frequency in Korea was similar to that in Indonesia. In 
Table II. Characteristics of Waldeyer's ring lymphomas among Asian countries.

\begin{tabular}{|c|c|c|c|c|c|c|}
\hline \multirow[b]{2}{*}{ Characteristics } & \multicolumn{2}{|c|}{ Lower WR } & \multicolumn{2}{|c|}{ Upper WR } & \multicolumn{2}{|c|}{ Total WR } \\
\hline & DLBCL & NKTCL & DLBCL & NKTCL & DLBCL & NKTCL \\
\hline \multicolumn{7}{|c|}{ Age range $(\text { median })^{\mathrm{a}}$} \\
\hline Indonesia & $17-82(50)$ & - & $26-99(51)$ & $38-45(42)$ & $17-99(50)$ & $38-45(42)$ \\
\hline China & $7-81(63)$ & $21-49(43)$ & $43-78(54)$ & $15-53(35)$ & $7-81(63)$ & $15-53(39)$ \\
\hline Korea & $9-84(57)$ & $45-53(48)$ & $21-78(50)$ & $20-60(41)$ & $9-84(57)$ & $20-60(43)$ \\
\hline Japan & $23-87(69)$ & 73 & $57-63(60)$ & $22-74(56)$ & $23-87(68)$ & $22-74(65)$ \\
\hline All countries & & & & & $7-99(57)$ & $15-74(43)$ \\
\hline \multicolumn{7}{|c|}{ Age $>60$ years, No. $(\%)$} \\
\hline Indonesia & $18(25.7)$ & $0 \quad(0)$ & $5(26.3)$ & $0 \quad(0)$ & $23(25.8)$ & $(0)$ \\
\hline China & $11(55.0)$ & $0 \quad(0)$ & $1(33.3)$ & $0 \quad(0)$ & $12(52.2)$ & $0 \quad(0)$ \\
\hline Korea & $21(35.0)$ & $0 \quad(0)$ & $1(20.0)$ & $0 \quad(0)$ & $22(33.8)$ & $0 \quad(0)$ \\
\hline Japan & $34(70.8)$ & $1(100)$ & $1(50.0)$ & $2(40)$ & $35(70.0)$ & $3(50.0)$ \\
\hline All countries & & & & & $92(40.5)$ & $3(8.8)$ \\
\hline \multicolumn{7}{|c|}{ Male:female ratio } \\
\hline Indonesia & $37: 33$ & $0: 0$ & $13: 6$ & $2: 0$ & $50: 39$ & $2: 0$ \\
\hline China & $12: 8$ & $2: 1$ & $2: 1$ & $2: 3$ & $14: 9$ & $4: 4$ \\
\hline Korea & $35: 25$ & $2: 1$ & $2: 3$ & $12: 3$ & $37: 28$ & $14: 4$ \\
\hline Japan & $28: 20$ & $1: 0$ & $1: 1$ & $2: 3$ & $29: 21$ & $3: 3$ \\
\hline All countries & & & & & 130:97 & $23: 11$ \\
\hline
\end{tabular}

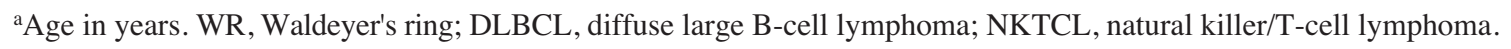

Table III. Epstein-Barr virus-positive rates by histologic type in Waldeyer's ring lymphoma.

\begin{tabular}{|c|c|c|c|c|c|}
\hline \multirow[b]{2}{*}{ Country } & \multirow[b]{2}{*}{ Location of WR } & \multicolumn{4}{|c|}{ \% EBV-positive cases (EBV-positive/analyzed cases) } \\
\hline & & DLBCL & FL & NKTCL & PTCL-u \\
\hline \multirow[t]{3}{*}{ Indonesia } & Lower & $1.4(1 / 70)$ & & & \\
\hline & Upper & $5.3(1 / 19)$ & & $100 \quad(2 / 2)$ & \\
\hline & Total & $2.2(2 / 89)$ & & $100 \quad(2 / 2)$ & \\
\hline \multirow[t]{3}{*}{ China } & Lower & $0(0 / 20)$ & & $100 \quad(3 / 3)$ & \\
\hline & Upper & $33.3(1 / 3)$ & & $100 \quad(5 / 5)$ & \\
\hline & Total & $4.3(1 / 23)$ & & $100 \quad(8 / 8)$ & \\
\hline \multirow[t]{3}{*}{ Korea } & Lower & $6.3(3 / 48)$ & $0(0 / 5)$ & $50.0 \quad(1 / 2)$ & $0(0 / 6)$ \\
\hline & Upper & $0 \quad(0 / 4)$ & & $83.3(10 / 12)$ & $0(0 / 1)$ \\
\hline & Total & $5.8(3 / 52)$ & $0(0 / 5)$ & $78.6(11 / 14)$ & $0(0 / 7)$ \\
\hline \multirow[t]{3}{*}{ Japan } & Lower & $6.3(3 / 48)$ & $0(0 / 1)$ & $100 \quad(1 / 1)$ & $100(1 / 1)$ \\
\hline & Upper & $0 \quad(0 / 2)$ & $0(0 / 1)$ & $80.0 \quad(4 / 5)$ & $0(0 / 1)$ \\
\hline & Total & $6.0(3 / 50)$ & $0(0 / 2)$ & $83.3 \quad(5 / 6)$ & $50(1 / 2)$ \\
\hline
\end{tabular}

EBV, Epstein-Barr virus; DLBCL, diffuse large B-cell lymphoma; FL, follicular lymphoma; NKTCL, natural killer/T-cell lymphoma; PTCL-u, peripheral T-cell lymphoma, unspecified. 
A

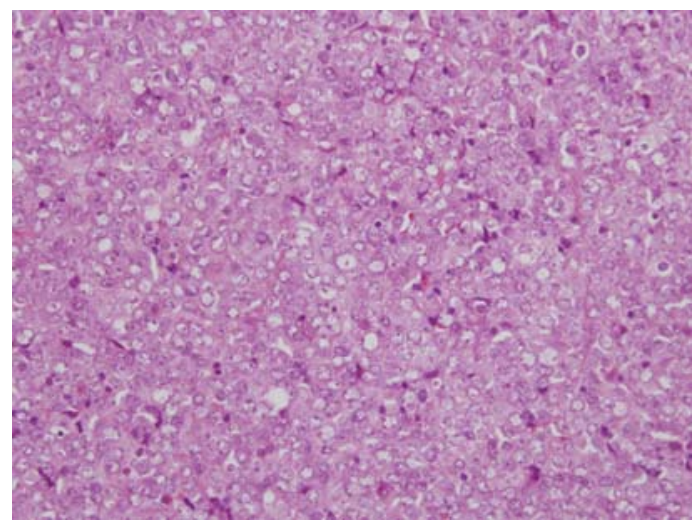

C

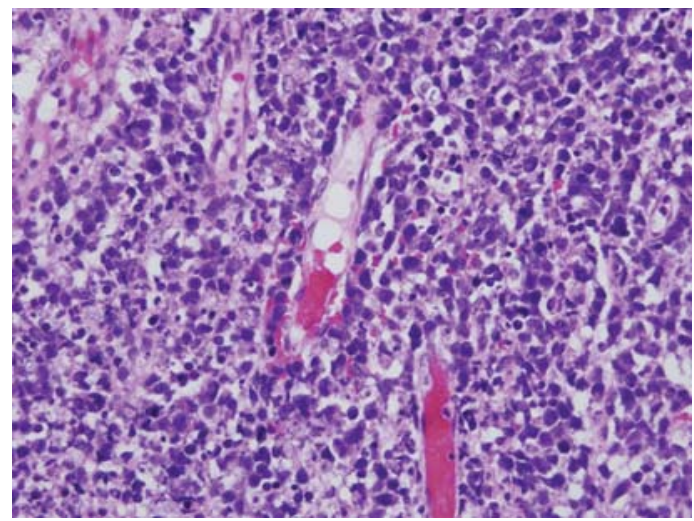

B

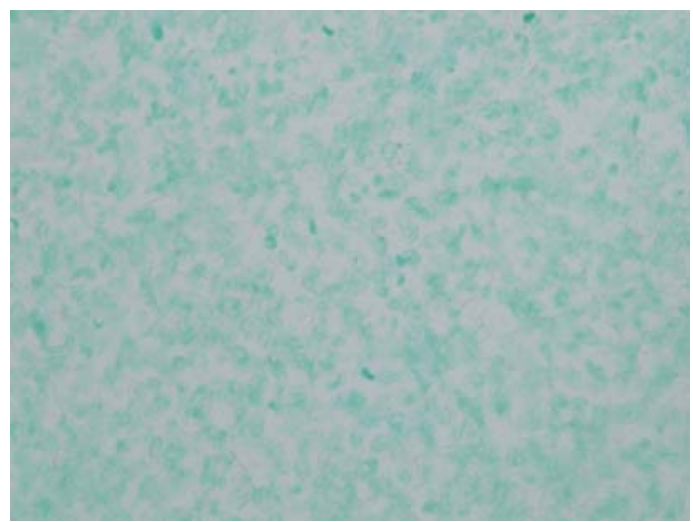

D

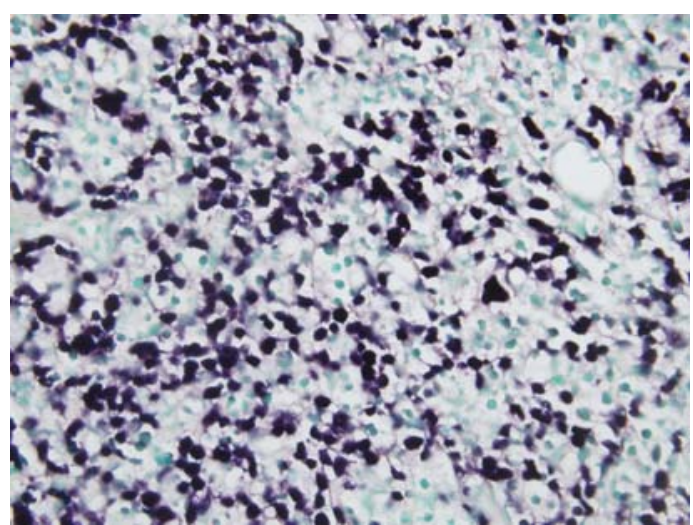

Figure 1. (A) Diffuse large B-cell lymphoma in an Indonesian case. Large lymphoid cells have a diffuse pattern of proliferation (H\&E). (B) In situ hybridization with EBER-1 probe yielded no signals in the nuclei. (C) Natural killer/T-cell lymphoma exhibiting polymorphous figures with medium- to large-sized lymphoid cells in a Japanese case (H\&E). (D) In situ hybridization yielded numerous positive signals. Magnification (A-D), x400.

general, WRL occurred more frequently in males than in females, irrespective of histologic type.

The EBV-positive rate in WRL, summarized in Table III, was similar among the same histologic type irrespective of country. The EBV-positive rate in NKTCL (78.6-100\%) was much higher than in DLBCL (2.2-6\%) (Fig. 1).

\section{Discussion}

Environmental and lifestyle factors, including infectious organisms, drugs, solvents, and other chemicals, along with occupation and genetic factors, may play a role in the etiology of NHL (9). It can therefore be postulated that the characteristics of WRL will vary among Asian countries. In terms of histologic type, in all countries DLBCL was predominantly found in the lower WR. NKTCL was the most common type of WRL in the upper WR in China, Korea, and Japan with frequencies of 50-62.5\%, but not in Indonesia, where it had a frequency of $9.5 \%$. Previous epidemiological studies have revealed the clustering of patients with nasal NKTCL in East Asian countries including Japan, China and Korea $(10,11)$, indicating that the Northern Mongoloid ethnic group is more susceptible to the disease. Native Indonesian people belong to the Southern Mongoloid ethnic group. Therefore, a difference in ethnicity might explain differences in the frequency of NKTCL occurrence. Additionally, our recent study on lifestyle and environmental factors in the development of NKTCL of the nasal cavity revealed that exposure to pesticides and chemical solvents might cause NKTCL (12), suggesting that environmental factors play a role in NKTCL development.
Studies on the incidence rate of nasal NKTCL in Indonesia will further elucidate this finding.

In total, the frequency of patients over 60 years of age $(8.8 \%)$ was significantly lower among NKTCL cases than DLBCL cases $(40.5 \%)$. Limited to the lower WR, patients with DLBCL were significantly younger in Indonesia (median 50 years) than in China (median 63 years) or Japan (median 69 years). Earlier disease onset in NKTCL compared to DLBCL, and differences in age among DLBCL cases in the lower WR, might reflect the influence of different environmental factors on lymphomagenesis according to disease type or country.

The EBV-positive rate for NKTCL in the upper and lower WR was high, as has been reported in nasal NKTCL. EBV infects B lymphocytes through the CD21 receptor. However, DLBCL in WR infrequently contained the EBV genome. This is consistent with DLBCL in other sites.

In conclusion, the present study revealed differences in the histologic type and age distribution of WRL in East and Southeast Asian countries according to the location of lesions in WR. Similar studies in other regions may further elucidate the etiology of WRL.

\section{Acknowledgements}

This research study was supported in part by grants from the Ministry of Education, Science, Culture and Sports, Japan (nos. 16390105 and 18014015). The authors thank Ms. Keiko Fujikawa, Ms. Megumi Sugano, Ms. Takako Sawamura and Ms. Etsuko Maeno for their technical assistance. 


\section{References}

1. Menarquez J, Mollejo M, Carrion R, et al: Waldeyer ring lymphomas. A clinicopathological study of 79 cases. Histopathology 24: 13-22, 1994.

2. Ezzat AA, Ibrahim EM, El Weshi AN, Khafaga YM, AlJurf M, Martin JM, Ajarim DS, Bazarbashi SN, Stuart RK and Zucca E: Localized non-Hodgkin's lymphoma of Waldeyer's ring: clinical features, management, and prognosis of 130 adult patients. Head Neck 23: 547-558, 2001

3. Harabuchi Y, Yamanaka N, Kataura A, Imai S, Kinoshita T, Mizuno $\mathrm{F}$ amd Osato T: Epstein-Barr virus in nasal T-cell lymphomas in patients with lethal midline granuloma. Lancet 335 : 128-130, 1990 .

4. Aozasa K, Takakuwa T, Hongyo T and Yang WI: Nasal NK/ T-cell lymphoma: epidemiology and pathogenesis. Int J Hematol 87: 110-117, 2008.

5. Weiss LM, Gaffey MJ, Chen YY and Frierson HF Jr: Frequency of Epstein-Barr viral DNA in 'Western' sinonasal and Waldeyer's ring non-Hodgkin's lymphomas. Am J Surg Pathol 16: 156-162, 1992.

6. Kanavaros P, Briere J, Lescs MC and Gaulard P: Epstein-Barr virus in non-Hodgkin's lymphomas of the upper respiratory tract: association with sinonasal localization and expression of $\mathrm{NK}$ and/ or T-cell antigens by tumour cells. J Pathol 178: 297-302, 1996.
7. Ott G, Kalla J, Ott MM and Müller-Hermelink HK: The Epstein-Barr virus in malignant non-Hodgkin's lymphoma of the upper aerodigestive tract. Diagn Mol Pathol 6: 134-139, 1997.

8. Weiss LM, Jaffe ES, Liu XF, Chen YY, Shibata D and Medeiros LJ: Detection and localization of Epstein-Barr viral genomes in angioimmunoblastic lymphadenopathy and angioimmunoblastic lymphadenopathy-like lymphoma. Blood 79: 1789-1795, 1992.

9. Chiu BC and Weisenburger DD: An update of the epidemiology of non-Hodgkin's lymphoma. Clin Lymphoma 4: 161-168, 2003.

10. Aozasa K, Ohsawa M, Tajima K, Sasaki R, Maeda H, Matsunaga T and Friedmann I: Nation-wide study of lethal midline granuloma in Japan: frequencies of Wegener's granulomatosis, polymorphic reticulosis, malignant lymphoma and other related conditions. Int J Cancer 44: 63-66, 1989.

11. Aozasa K, Yang WJ, Lee YB, Pan WS, Wy YF, Horiuchi K, Hyun BH and Tajima K: Lethal midline granuloma in Seoul (Korea) and Shanghai (China). Int J Cancer 52: 673-674, 1992.

12. Xu JX, Hoshida Y, Yang WI, Inohara H, Kubo T, Kim GE, Yoon JH, Kojya S, Bandoh N, Harabuchi Y, Tsutsumi K, Koizuka I, Jia XS, Kirihata M, Tsukuma H and Aozasa K: Lifestyle and environmental factors in the development of nasal NK/ T-cell lymphoma: a case-control study in East Asia. Int J Cancer 120: 406-410, 2007 